\title{
Vázquez Montalbán i el futbol: subcultura, sociabilitat i educació sentimental
}

\author{
Conrad Vilanou i Torrano i Clara Domènech i Vivas (Universitat de Barcelona)
}

Jordi Osúa Quintana, Vázquez Montalbán. Futbol y política.

Barcelona, Editorial Base, 2019, 249 pàg.

D'entrada hem de dir que l'autor d'aquest llibre no és un desconegut pels lectors de Temps d'Educació, atès que ha publicat en aquesta revista un parell d'articles en relació a la qüestió esportiva amb el futbol com a eix central de la reflexió, però amb una mirada sempre oberta a tota pràctica esportiva. Ens referim, en concret, als articles «Implicacions educatives dels símbols esportius» (2010) i «Manuel Vázquez Montalbán i l'esport: una necessitat pedagògica» (2019) que citem en l'apartat bibliogràfic. Val a dir que Jordi Osúa va presentar l'any 2013, a l'INEFC de Barcelona, la tesi doctoral El deporte en la vida y obra de Manuel Vázquez Montalbán, dirigida pel professor Javier Olivera Betran (1952-2018), recentment traspassat, una mort sobtada que ha tallat una brillant carrera acadèmica que encara podia donar més fruits. En aquest punt, podem recordar que Javier Olivera va defensar el 1997 una tesi sobre la figura de José María Cagigal, vida, obra y pensamiento en torno a la educación física y el deporte, també llegida a I'INEFC de Barcelona i dirigida pel professor Antoni Petrus. Per aquelles mateixes dates, el 1996, el Comitè Olímpic Espanyol va editar una selecció dels escrits de Cagigal amb el títol d'Obras selectas, en tres volums. Sense cap mena de dubte Cagigal constitueix, adés $\mathrm{i}$ ara, un dels referents de l'humanisme esportiu, cosa lògica si tenim en compte que posseïa una sòlida formació filosòfica i teològica, més encara si pensem que havia estat membre de la Companyia de Jesús, abans de la seva secularització. Podem consignar, a títol de simple recordatori, que Cagigal va ser deixeble del teòleg austríac Hugo Rahner, que tot i ser menys conegut que el seu germà Karl, ambdós jesuïtes, també va atresorar un ben guanyat prestigi intel.lectual. Així les coses, no podem deixar de mencionar el seu llibre Der spielende Mensch (1952) que es va traduir fa uns anys amb el títol d'El hombre lúdico.

Serveixi aquesta llarga introducció per posar de manifest que des del camp catòlic es van fer esforços per trobar una base teològica lúdica que justifiqués no només el joc, sinó també l'esport, sempre d'acord amb la trajectòria de la filosofia perenne, matriu de I'humanisme cristià. D'acord amb el que diem, convé parar atenció en què la virtut aristotèlica de l'eutrapèlia va ser cristianitzada per Tomàs d'Aquino i que, llevat d'una millor expressió, podem traduir per jovialitat. Per consegüent, és lícit que l'ésser humà jugui $i$ es diverteixi amb capteniment i d'una manera convenient, però tenint en compte que no pot caure en els extrems de la plagasitat, la comicitat grollera i la ludopatia, o, ben contràriament, en una actitud esquiva i desagradosa allunyada de la necessària i edificant recreació (Vilanou i Bantulà, 2013). Potser caldria també recordar que l'existència d'un Deus ludens $(\operatorname{Pr} 8,30)$ justifica l'existència d'un Homo ludens (Huizinga), 
des del moment que l'ésser humà ha estat creat a imatge i semblança divina. Cal notar, a més, que quan parlem de la filosofia aristotèlica i tomista, ens movem en un terme mig, que s'allunya dels excessos, i que, pel que fa al cas que ens ocupa, propugna una actitud d'alegria ben entesa, d'esbarjo i delectació, que ha de presidir el joc i qualsevol altre passatemps. En conseqüència, no pot sorprendre que Sant Francesc de Sales, a la Introducció a la vida devota (1609), es mostrés partidari de la sana diversió, d'acord amb aquesta virtut, per la qual cosa no s'oposava als jocs i passatemps, quelcom que va prohibir i perseguir la moral calvinista, a la qual el sant -bisbe de Ginebra- no va deixar d'oposar-se. En últim terme, sembla ben evident que hi ha bases suficients, dins l'òrbita del pensament catòlic, per mostrar-se favorable als jocs i a l'esport, sempre que això no comporti una passió desenfrenada. Doncs bé, al professor Osúa el podem situar sota el deixant d'aquest pensament cristià que accepta el joc i la pràctica esportiva i que, al seu torn, constata que l'esport ha esdevingut al llarg del segle passat i del que portem del present una mena de substitució de la fe cristiana, fins al punt de convertir-se en una mena de religió laica. Al cap i a la fi, grans teòrics de l'esport com Carl Diem, el factòtum dels Jocs Olímpics de Berlín de 1936, i el baró Pierre de Coubertin, restaurador dels Jocs Olímpics (Atenes, 1896) que va comptar amb el suport del pare dominic Henri Didon que va encunyar el lema olímpic ( $C i$ tius, Altius, Fortius), van defensar les arrels religioses de l'esport i, el que no és menys destacat, van arribar a parlar d'una religió atlètica que, per alguns com els nazis, podia empeltar-se amb la saba del paganisme hel-lènic $i$ els ideals de la bellesa clàssica.
A la vista del hem exposat, podem ressaltar que en l'univers mental del professor Osúa (1975) la religió ocupa un Iloc preferent i així no ens pot sorprendre que hagi dedicat diversos treballs a analitzar les relacions entre l'esport i la religió. En aquest sentit, s'ha de mencionar el llibre Esport contemporani $i$ socialitat postmoderna. Entre la identitat i la globalització, premi Serra i Moret (2009), en què planteja l'esport com una religió universal que s'adiu al marc de la globalització econòmica, política i cultural, però alhora com un element que possibilita la identificació amb les identitats locals. D'aquesta manera, l'esport pot ser un instrument per viure en una societat global sense renunciar a les pròpies arrels. De a més a més, en el primer article que va aparèixer en les pàgines de Temps d'Educació (2010) va emfasitzar les implicacions pedagògiques dels símbols esportius. Ben mirat, aquesta simbiosi entre l'esport i la religió constitueix una idea-força del seu pensament que ha desgranat en petites píndoles en alguns articles que indiquem en l'apartat bibliogràfic i, naturalment, en els seus llibres.

Així, doncs, amb el transfons d'aquesta visió religiosa del fenomen esportiu, Jordi Osúa s'ha centrat en aquesta ocasió Vázquez Montalbán. Futbol y política (2019) en el paper del futbol i la política en l'obra de Manuel Vázquez Montalbán (1939-2003), un llibre que dóna peu a la present reflexió bibliogràfica i que va obtenir el xxx Premio de Ensayo Becerro de Bengoa, corresponent a l'edició de 2018, convocat per la Diputació Foral d'Àlaba. Tinguem present que uns mesos abans, també va aparèixer un altre llibre d'aquest mateix autor, Manuel Vázquez Montalbán. Barça, cultura iesport (2018), en què Jordi Osúa fa una introducció biogràfica on explica els lligams de l'escriptor barceloní amb el club i la vivència religiosa de l'afició barcelonista. Hem de tenir ben present, igualment, que Osúa 
ens ofereix en aquesta obra una recopilació dels articles barcelonistes més rellevants de Vázquez Montalbán, on es pot copsar el caràcter extraesportiu del FC Barcelona i observar el futbol com un laboratori on afloren les tensions polítiques i socials.

Precisament per això ens interessa posar de manifest que en la cosmovisió (Weltanschauung) del professor Osúa es detecta una dimensió religiosa, sobre la base de la tradició de la religió cristiana, tal com es va formalitzar en el Credo de Nicea (325 d. C.) i va assumir I'humanisme fins arribar a la convocatòria de Concili Vaticà Segon (1962-1965), que va comportar un aggiornamento o actualització del missatge cristià d'acord amb els signes del temps. No per atzar, els Jocs Olímpics de 1960, quan Joan XXIIi ja havia substituït Pius XII en el papat, es van disputar a Roma, en uns moments que hom es trobava a l'espera de canvis que es van produir amb la convocatòria del Concili (1962), iniciat per Joan XXIII i clausurat per Pau vı. Val a dir que el seu nomenament com a summe pontífex el juny de 1963 va permetre que el franquisme dictés un indult que va facilitar l'alliberament de Vázquez Montalbán tancat a la presó de Lleida, on romania per les seves activitats polítiques després d'un Consell de Guerra, segons s'expressa en el llibre i es fa constar en el colofó de l'obra que ens ocupa, datada el 2019, que va coincidir amb els 56 anys de la seva llibertat. «Dieron la noticia [por la radio del patio de la cárcel] como si se tratase de la retransmisión de un partido de futbol. Era como si el locutor fuese José María García porque fue una retransmisión vibrante, emotiva: "Se está muriendo, jy el cardenal camarlengo sale al balcón! (...) y entonces dijo: "El Papa ha muerto", y seguidamente fue un estallido de júbilo, de aplauso».

En un altre ordre de coses, està clar que Manuel Vázquez Montalbán serveix al professor Osúa com un pretext per reflexionar sobre l'esport i demostrar que constitueix una veritable religió que, com sabem, va ser rebutjada per la majoria d'intel.lectuals que van identificar amb una mena d'opi del poble, tot i que el règim soviètic havia donat suport a la seva pràctica per bé que I'URSS es va distanciar de l'esport burgès, associat al moviment olímpic, encara que a partir dels Jocs de Hèlsinki (1952) el país dels soviets va concórrer assíduament. Però la cosa venia de molt abans, primer perquè l'esport va esdevenir en la dècada dels anys vint un fenomen de masses amb el creixement del professionalisme i, després i sobretot, per la manipulació ideològica que el nazisme va fer dels Jocs Olímpics de Berlín (1936). És per això que la intel-lectualitat es va mostrar crítica amb l'esport, per ser una instància d'alienament que desmobilitzava la participació política i sindical, a benefici dels governs autoritaris i totalitaris. Amb tot, va haver intel-lectuals com Jean Giradoux i Curzio Malaparte que no van dubtar en donar suport a l'esport, tal com ho han recordat els professors Angel Pascual i Mauro Valenciano en la presentació del dossier «Cos i esport: lectures crítiques i genealògiques», inclòs en el número 57 d'aquesta revista (segon semestre de 2019). En aquesta mateixa direcció, anotem la revisió bibliogràfica que a propòsit de Curzio Malaparte i el ciclisme italià, va assajar el professor Conrad Vilanou en la reflexió «Fausto Coppi, una icona dels temps moderns a l'Europa de postguerra», quan va comparar -tot seguint Malaparteels ciclistes Gino Bartali i Fausto Coppi, publicada en aquesta revista el 2016. Per la nostra part, ens ve a la memòria el recent llibre de Pier Paolo Pasolini sobre l'esport en què comenta que durant la seva joventut va ser de jove un tiffosi del Bologna, un altre intel.lectual a favor del futbol com Albert Camus i, entre els d'aquí, podem esmentar Joan Crexells. Vist el que diem, ens 
hem d'apressar a afegir que de la mateixa que Palmiro Togliatti -dirigent del Partit Comunista italià i referent intel-lectual de Vázquez Montalbán-era un afeccionat a la Juventus de Torí, Manuel Vázquez Montalbán va ser, des de la seva infància transcorreguda al barri del Raval, un afeccionat al Barça. A més, i així ho recorda Jordi Osúa, va ser fill de dues famílies immigrants, d'origen murcià pel que fa a la mare, de procedència gallega en relació el pare, que va patir la repressió franquista en ser empresonat durant diversos anys pel seu compromís republicà de manera que no el va poder conèixer durant els primers anys de la seva infància. Per tot plegat, resulta lògic que Vázquez Montalbán sentís preferència pel Barça i pel Deportivo de La Corunya. «El FC Barcelona actuó como un elemento subcultural de integración social que ayudó al pequeño Manuel, hijo de una barcelonesa con raíces murcianas y de un inmigrante gallego, a sentirse identificado con algunos de los símbolos de la cultura catalana» (p. 25).

Entre els mèrits de Vázquez Montalban està l'haver dedicat a l'esport -i molt especialment al futbol- una atenció impossible de sospitar en una persona d'esquerres i, a més, durant els anys del franquisme. I és evident que el mèrit del professor Jordi Osúa estreba en haver posat el focus en aquesta vessant esportiva del pensament de Vázquez Montalbán que, tot i reconèixer en el món de l'esport una manifestació subcultural, va saber valorar el paper que va tenir durant molts anys per promoure l'educació sentimental -o, el que és quasi bé el mateix, la sociabilitat- d'unes generacions orfes de llibertat política i que van substituir el debat polític per les històries amoroses en el cas de les dones i les futbolístiques pel fa els homes. I si tot això va ser factible, és deu justament a les ones radiofòniques que a través dels serials de Guillermo Sautier Casaseca (Lo que no muere,
Ama Rosa) i de les retransmissions futbolístiques van conformar l'educació sentimental de diverses generacions d'espanyols. Per ara, volem fer notar el paper que Jordi Osúa -tot estrafent Vázquez Montalbán- concedeix a Matías Prats, un locutor vinculat a l'èpica del règim franquista, amb la narració del famós gol de Zarra que va eliminar Anglaterra en el campionat del món de futbol del Brasil (1950) i que es va convertir, en una època en què Espanya no gaudia del reconeixement internacional, en una proesa semblant a la dels terços de Flandes. Naturalment, al costat de Matías Prats van sorgir un seguit de locutors, i aquí cal esmentar Enrique Mariñas, que feia parella amb l'anterior, que van forjar aquella educació sentimental en què els partits de futbol s'havien d'imaginar mentalment a través de les ones de la ràdio, tot esperant que el NO-DO passés alguna jugada estel.lar o algun gol antològic. També a Catalunya, locutors com ara Joan Viñas i Miguel Ángel Valdivieso, van contribuir a perfilar aquella educació sentimental, però sense l'èmfasi patriòtic que la parella Prats i Mariñas va saber transmetre a major glòria del franquisme. Podem consignar que quan hom recorda aquella època franquista recupera imatges com el «Marcador simultáneo dardo», on els noms dels equips s'identificaven a través de firmes comercials, o bé el Carrusel Deportivo que a partir de 1954 va arribar a les llars d'aquells que seguien amb atenció la marxa de les travesses esportives que es van posar en marxa el 1946. I tot això sense perdre de vista la rivalitat dels clubs, no només la del Barça amb el Reial Madrid, sinó també la del Barça amb el RCD Espanyol, tal com es va poder comprovar en la final de la Copa del Rei disputada l'any 1957 al vell estadi de Montjuïc entre ambdós equips i que els blaugranes van guanyar per 1 a 0 amb un gol de Sampedro. I això va succeir uns pocs anys després del famós Barça de les cinc copes liderat per 
Ladislau Kubala i que Joan Manuel Serrat va immortalitzar en la cançó Temps era temps, sense oblidar el famós cas del fixatge frustrat pel Barça d'Alfredo Di Stefano, que va tenir lloc el 1953 i que Vázquez Montal bán va tractar en diverses ocasions.

Tampoc podem oblidar que en els barris populars de Barcelona, en el Raval, en el Gòtic, en les zones adjacents al mercat de Santa Caterina, en la Ribera, en la Barceloneta, és a dir, a la Barcelona de ciutat vella, era costum que els bars reproduïssin en pissarres o en pintura sobre els miralls els resultats de futbol el diumenge a la tarda, i que els cartells dels combats de boxa que es celebraven al Price pengessin de les parets de botigues i establiments. Estem davant d'un fenomen que es devia repetir en altres barris populars (Sants, Gràcia, Sant Andreu, Horta, etc.) i, adesiara, en molts pobles on existien establiments amb el nom de cafè Sport (a Bellcaire d'Urgell, Olost de Lluçanès, Olot o Sant Quirze de Besora encara es poden trobar) o similars (Derby, Córner, Rugbi, etc.) on, a banda de servir d'aixopluc al futbol local, existien tertúlies en què els debats futbolístics i esportius pujaven sovint de to, a redós de la premsa esportiva que circulava de mà en mà. Fa anys el doctor Ramon Balius va dedicar un article, publicat el 1991, sobre una exposició de trenta-cinc olis del pintor Lluis Pou sobre diversos bars amb noms esportius, moment que va aprofitar per reconèixer que «el bar-sport és a Catalunya una veritable i entranyable institució que ha estat el bressol de nombrosos clubs, especialment de futbol» (Balius, 1991, p. 227). I això sense oblidar les discussions futbolístiques a Canaletes, quan la rivalitat entre el Barça i l'Espanyol era ben viva. Altrament, en la memòria dels barcelonins encara romania el record de grans figures de la boxa, com ara Ricard Alís i Josep Joan Gironès que es va veure obligat a marxar $a$
I'exili i que han estat objecte de diverses monografies. La cosa, emperò, venia d'abans de la Guerra Civil amb boxejadors esbojarrats com Pedro Roca que Julià Guillamón ha recuperat i que va escriure un Ilibre en castellà quasi bé de manera automàtica i que constitueix una bona radiografia d'aquell món subcultural dels anys trenta. Llevat d'això, la figura del boxador sonat tampoc era infreqüent pels carrers i places de postguerra, atès que sovint eren els que repartien els cartells anunciadors de les vetllades pugilístiques. No debades, Vázquez Montalban va adoptar el pseudònim de Luis Dávila -també va utilitzar el de Sixto Cámara, en honor del líder del moviment obrer del segle XIX- perquè li recordava l'atmosfera de la boxa que a més el cinema americà, amb pel.lícules en blanc i negre, havia contribuït a difondre a través de les sales d'exhibició, amb sessions dobles que juntament amb el NO-DO, van tenir un paper cabdal en l'educació sentimental d'aquella època. Arribats en aquest punt, convé recordar la pel.lícula de Kirk Douglas que aquí es va conèixer com El ídolo de barro (1949), que va contribuir a divulgar el món de la boxa, en un moment en què l'esport -ja fos el futbol o la boxa i, també, el ciclisme amb figures com Marià Cañardo i Miquel Poblet- començaven a minar el prestigi que els toros tenien en una ciutat com Barcelona que, fins poc abans de la dècada dels setanta, va tenir dues places (Monumental i Les Arenes) en actiu, alhora que funcionaven algunes penyes taurines històriques a la ciutat Comtal com la de «Los de Gallito y Belmonte» que també constituïen instàncies de sociabilitat.

Amb aquest panorama de fons, el Ilibre que tenim a les mans constitueix una eina eficaç per analitzar la dinàmica d'aquella educació sentimental del franquisme, connotada políticament i que Vázquez Montalbán, lector de Gramsci i 
militant del PSUC, va abordar des de la «perspectiva subcultural destinada tanto a valorar la función de la cultura de masas para las clases populares como a denunciar su manipulación ideológica al servicio del Régimen» (p. 32). D'acord amb aquest enfocament, els escassos èxits del futbol espanyol durant el franquisme, a banda del gol de Zarra ja esmentat convé tenir en compte el Campionat d'Europa aconseguit a Madrid el 1964 amb un gol de Marcelino davant I'URSS, són valorats per Vázquez Montalbán que «defiende el valor de la cultura de masas frente a la concepción burguesa y marxista que considera la subcultura únicamente como un medio de alienación en manos del poder establecido» (p. 38). A parer de Vázquez Montalbán, sempre interpretat per Jordi Osúa, el tàndem Franco (seguidor del Reial Madrid) i Santiago Bernabéu (president del club blanc) té molt a veure en la gestació del «nacionalfutbolisme» que es pot considerar un complement del «nacionalcatolicisme». Si s'ha fet famós el «pa i circ» de Juvenal, que Osúa recupera, es pot dir que la fórmula del franquisme va ser, més aviat, futbol i missa, el primer pels homes, la segona per dones i criatures. Pel general, els homes havien d'anar a missa en les grans festivitats i sempre que les cerimònies (bateigs, comunions, casaments, etc.) ho requerissin, mentre que les dones cobertes amb mantellina hi concorrien cada setmana.

En mig d'aquest estat de coses, el Barça va representar ser «més que un club», segons feliç expressió de Narcís de Carreras, frase pronunciada en ocasió de la final de la Copa del Generalíssim disputada el 1968 entre el Reial Madrid i el Barça, que van guanyar els blaugranes per 1 a 0 . Pel seu cantó, el Reial Madrid va esdevenir un emblema victoriós pel règim que a més exportava arreu, en un moment en què Espanya quedava bastant al marge en el concert de les nacions, sense poder entrar a l'ONU fins el 1955 poc abans de la visita del president Eisenhower a Madrid el desembre de 1959. No obstant això, la simbologia política del Barça procedia de l'etapa de la Dictadura de Primo de Rivera quan el club l'any 1925 va ser multat i clausurat el camp per haver xiulat la marxa Reial en un partit amistós amb el Júpiter dedicat a l'Orfeó Català, mentre va aplaudir I'himne anglès, interpretat per la banda de I'armada anglesa ancorada al port de Barcelona. Pocs mesos després, al camp de Les Corts, que feia poc que s'havia inaugurat (1922), es va d'haver de suspendre un partit del Barça amb l'Espanyol, en uns moments de gran rivalitat esportiva $i$, per extensió, política, en atenció a la significació d'ambdós equips, aspectes que Vázquez Montalbán també té ben presents en la seva anàlisi. «Después de la derrota en la Guerra Civil, el Barça pagó un precio muy alto por su adscripción política. Un compromiso que le había llevado a organizar una gira para recaudar fondos destinados a la causa republicana. Incluso estuvo a punto de desaparecer» (p. 157).

Vistes així les coses, podem considerar que Vázquez Montalbán va ser un intel.lectual atípic, que no va observar les orientacions dogmàtiques d'altres intel.lectuals orgànics que ho van supeditar tot al partit, i que tampoc va voler rebutjar -com va fer un sector important de la burgesia catalana- els esports populars a benefici d'altres pràctiques més elitistes com el tennis, I'hoquei herba, el polo, l'automobilisme, etc. Tot amb tot, i segons el que afirma Jordi Osúa, «la aproximación subcultural al fútbol finalizará a mediados de los años setenta cuando Vázquez Montalbán considere realizada su contribución a este campo» (p. 40). Lògicament, amb la mort del dictador les coses havien canviat i el futbol adquiria noves connotacions, amb 
figures com Pablo Porta -amb un fosc passat franquista en ser un dels capitosts del SEU- que substituïa noms llegendaris com el de Santiago Bernabéu, caporal de l'exèrcit franquista quan les tropes nacionals van entrar a Barcelona el 26 de gener de 1939. Però tot $i$ això, el futbol continuava mereixent l'atenció de Vázquez Montalbán, més encara si tenim en compte que Espanya va organitzar el Campionat del Món de 1982. Tampoc podem passar per alt que els diferents governs que s'han succeït sota la democràcia, des de Felipe González a José María Aznar, també es van interessar pel futbol, quelcom que va despertar els comentaris del periodista barceloní, conscient de la notorietat de les relacions entre el futbol i la política, nucli central del llibre que dóna peu a aquesta recensió. I això fins l'extrem que Vázquez Montalbán «opinaba que los clubes de futbol españoles no eran únicamente asociaciones Deportivas destinadas a ganar competiciones, sino que representaban algo más» (p. 139).

És obvi que resulta impossible donar compte i raó de tots els aspectes que es desprenen d'aquest esplèndid llibre que posa de manifest que Jordi Osúa és el millor coneixedor de la vessant esportiva de Manuel Vázquez Montalbán. Entre els múltiples mèrits d'aquest llibre, i sempre des d'una perspectiva pedagògica, ens interessa remarcar el triple paper que el futbol va tenir com element subcultural, generador de sociabilitat $\mathrm{i}$ agent de l'educació sentimental durant el franquisme, punts que Vázquez Montalbán no va menysprear com feien la majoria d'intel.lectuals. En canvi, ell va elaborar «una hermenèutica de l'esport emancipada de l'oficialisme de la retòrica marxista» ( $p$. 237), alhora que va treballar per salvar el hiatus entre la cultura burgesa i la subcultura proletària que es va llençar a l'espec- tacle de l'esport de masses. Si a Itàlia el ciclisme va tenir un paper fonamental en la configuració de la Itàlia post-feixista, quelcom similar va succeir a l'estat espanyol amb el futbol que es va posar al servei de la cohesió o unitat nacional que perseguia el franquisme.

D'aquesta manera, i com assenyala Jordi Osúa, Vázquez Montalbán actua a contracorrent puix no observa les ortodòxies dels partits polítics i tampoc segueix les modes intel.lectuals que rebutjaven, fins el menyspreu, la passió esportiva de les classes populars. Es tractava, ben mirat, d'un fenomen que afectava tothom, adults i infants, que col-leccionaven cromos dels ídols dels seus equips respectius. «No obstante, asume la esencia del marxismo al prescindir de especulaciones estériles y centrarse en el análisis de lo real. Una reflexión que no responde a un interés teórico y erudito, sino a la voluntad de transformar las condiciones sociales» (p. 237). Paga la pena insistir en què des d'una perspectiva pedagògica un dels grans mèrits del llibre que ens ocupa rau en haver posat de relleu la importància del futbol, una manifestació de la subcultura, com un instrument que va configurar la sentimentalitat popular. «Esta función se desarrolla especialmente durante el franquismo, cuando "asistir a un partido de fútbol era un acto de resistencia política". Pero también continúa en la democracia por la crisis de los partidos políticos y de la religión» (p. 237). Jordi Osúa ho rebla un xic més endavant amb el següent comentari, en què destaca de bell nou l'aportació de Vázquez Montalbán:

Rescata del olvido los mitos y los símbolos aso-
ciados a su infancia y adolescencia, en espe-
cial, el carácter epopéyico de las gestas de de-
terminados futbolistas o equipos (el Barça de
les Cinc Copes). En definitiva, el análisis sub-
cultural le permite ofrecer al pueblo instru-
mentos para defenderse de la alienación sub-
yacente en el futbol. Así como reivindicar su
valor individual (satisfacción de la necesidad 
épica) y social (participación y expresión de la cultura popular). (p. 238)

És hora de posar fi a aquest comentari que ultrapassa els límits estrictes del llibre que ens ocupa, i que ens ha portat a fer unes consideracions sobre la gènesi intel.lectual del professor Jordi Osúa que pot ajudar a entendre la seva filosofia de l'esport que es fonamenta en una dimensió religiosa o, si més, en una lectura religiosa del fenomen esportiu. D'una o altra manera, aquest aspecte també es troba en I'anàlisi de Vázquez Montalbán sobre el futbol, que valora com un producte subcultural, inherent a les classes populars i que, al seu torn, constitueix un element clau de l'educació sentimental i de la sociabilitat del proletariat i, fins i tot, de les classes mitjanes més baixes. Justament, podem afegir que hem compaginat la lectura d'aquest llibre amb la visió de la sèrie The English Game (estrenada el 20 de març de 2020 en la plataforma Netflix) sobre els orígens del futbol a Anglaterra i on, malgrat alguna tergiversació de la realitat, es reflecteix el procés que es va viure entre els 1878 i 1882 . Fou llavors quan el professionalisme es va introduir en aquest esport, a través dels patrons de les indústries tèxtils amb la intenció de donar una distracció pels treballadors de les fàbriques el dissabte per la tarda (la coneguda setmana anglesa) i afavorir així la sociabilitat més enllà dels tallers de les manufactures en uns moments de conflictivitat social. Els dos personatges centrals de la sèrie constitueixen dues figures certament històriques que, a més, serveixen per il.lustrar la lluita de classes que es va generar en aquells anys sobre els terrenys de joc i ens els despatxos de les organitzacions esportives regides pel principi de l'amateurisme i el fair-play. D'una banda, trobem el banquer i aristòcrata Arthur Kinnaird que representava l'esperit senyorívol i elitista dels alumnes de les Public schools britàniques que jugava en el Old Etonians, mentre per altra part apareix el nom de Fergus Suter, molt probablement el primer jugador professional que va cobrar per fitxar per clubs que van començar a retribuir monetàriament llurs jugadors. És segur que els puristes trobaran en la sèrie incongruències com la disputa el 1883 de la Football Association Cup Final entre el Old Etonians i el Blackburn Olympic i que van guanyar aquests últims per 2 a 1. De fet, Fergus Suter no jugava en aquest equip com explica la sèrie si no en el Blackburn Rovers que havia perdut la mateixa final, en l'edició de I'any anterior (temporada 1881-82) disputada també davant els Old Etonians per un gol a zero. Però més enllà d'aquests detalls, que segur apassionen els que elaboren estadístiques esportives, el cert és que a través de figures com Fergus Suter, i equips com els de Blackburn, ja sigui els Rovers o l'Olympic, que és el que va guanyar la final de 1883, és clar que a partir de començament de la dècada dels anys vuitanta del segle XIX el futbol s'havia fet professional i entrava de ple en la categoria de subcultural, sempre agradable als ulls dels historiadors britànics amb els seus tallers d'història. Oimés si tenim en compte que la victòria del Blackburn Olympic el 1883 va significar la primera victòria d'un equip format per jugadors provinents de les classes treballadores, en la competició Football Association Cup Final que es disputava des de 1872. Fins llavors, tot havien estat victòries d'equips universitaris, integrats per gentlemen, amb passat col-legial ja sigui a Oxford o Eton, si bé personatges com Arthur Kinnaird van ocupar càrrecs de relleu com la presidència de la Football Association durant trenta-tres anys (18901923) i, alhora, va ser responsable màxim d'organitzacions com el YMCA. A Catalunya, la cosa va trigar molt més en arribar i el futbol no va esdevenir un fenomen social de gran magnitud fins després de la Gran Guerra (1914-1918) i, nogensmenys, durant el franquisme. Sortosament tenim 
escriptors com ara Manuel Vázquez Montalbán que, en trencar els estereotips de la intel.lectualitat esquerrana, sempre reticent a acceptar el futbol, ens ha deixat una crònica sentimental de l'educació de l'època franquista, un aspecte en què Jordi Osúa ha centrat l'atenció i al qual agraïm aquest esforç i exhortem a què continuï per aquest camí a benefici de l'esport i de la memòria col-lectiva del país.

\section{Referències}

Balius i Juli, R. (1991) «Una exposició insòlita en el Museu de l'Esport. El barsport a Catalunya». Apunts. Medicina de l'Esport, XVII, núm. 109, p. 227-229.

Cagigal, J. M. (1996) Obras selectas. Madrid, Comité Olímpico Español, 3 vols.

Diem, C. (1966) Historia de los deportes. Barcelona, Caralt.

Coubertin, P. (2004) Lliçons de pedagogia esportiva. Vic, Eumo.

Guillamón, J. (2014) Jamás me verá nadie en el ring: la historia del boxeador Pedro Roca. Barcelona, Comanegra.

Osúa, J. (2009) Esport i religió: una aproximació fenomenològica. Barcelona, Fundació Joan MaragallClaret.

Osúa, J. (2010) «Implicacions educatives dels símbols esportius». Temps d'Educació, núm. 38, p. 263-280).

Osúa, J. (2011) Esport contemporani i socialitat postmoderna. Entre la identitat i la globalització. Barcelona, Generalitat de Catalunya.

Osúa, J. (2012) «Futbol, desconstructivisme i religió», Ars Brevis, 15, 2009, p. 322-351;

Osúa, J. (2012) «Esport, ascetisme i vida espiritual». Poblet, 24, p. 39-43.

Osúa, J. (2018) «Església i esport». Poblet, 39, p. 39-43.

Osúa, J. (Ed.) (2018) Manuel Vázquez Montalbán. Barça, cultura i esport. Barcelona, Base.
Osúa, J. (2019) «Manuel Vázquez Montalbán i l'esport: una necessitat pedagògica». Temps d'Educació, núm. 57, p. 153-173.

Pascual, A. i Valenciano, M. (2019 «Cos i esport: lectures crítiques i genealògiques». Temps d'Educació, núm. 57, p. 113-117.

Passolini, P. P. (2015) Sobre el deporte. Barcelona, Contra.

Rahner, H. (1997) El hombre lúdico. València, Edicep.

Roglan, J. (2007) Combat a mort: Gironès i els boxejadors perseguits pel franquisme. Barcelona, Angle editorial.

Vilanou, C. i Bantulà, J. (2013) «Sobre la eutrapelia, o la virtud del juego». Bordón, vol. 65, núm. 1, p. 47-58.

Vilanou, C. (2016) «Fausto Coppi, una icona dels temps moderns en l'Europa de postguerra». Temps d'Educació, núm. 50, p. 307-315. 